\title{
Vegetation changes in recent large-scale ecological restoration projects and subsequent impact on water resources in China's Loess Plateau
}

\author{
Shuai $\mathrm{Li}^{\text {a }}$, Wei Liang ${ }^{\mathrm{a}, \mathrm{b}, *}$, Bojie Fu ${ }^{\mathrm{b}}$, Yihe Lü ${ }^{\mathrm{b}}$, Shuyi Fu ${ }^{\mathrm{a}}$, Shuai Wang ${ }^{\mathrm{b}}$, Huimin $\mathrm{Su}^{\mathrm{a}}$ \\ a College of Tourism and Environment, Shaanxi Normal University, Xi'an 710119, China \\ b State Key Laboratory of Urban and Regional Ecology, Research Center for Eco-Environmental Sciences, Chinese Academy of Sciences, P.O. Box 2871, Beijing 100085, China
}

\section{H I G H L I G H T S}

- Satellite-derived vegetation index experienced significantly increasing trend.

- More evapotranspiration from restored vegetation is the primary reason for the reduced runoff index.

- Ecological restoration projects produce both positive and negative effects on the overall ecosystem services.
GR A P H I C A L A B S T R A C T

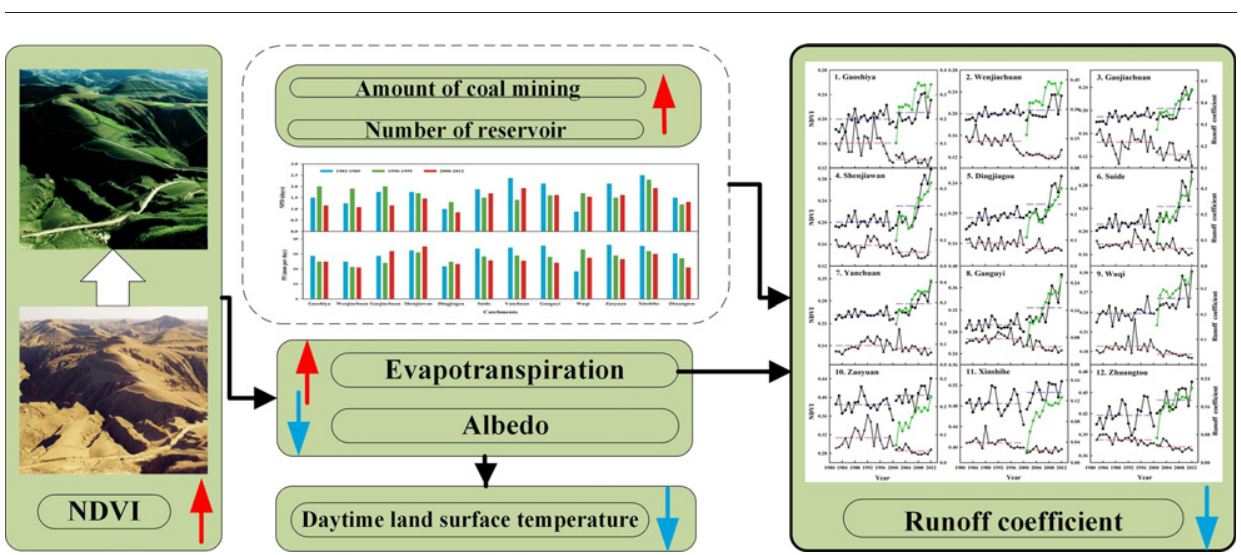

\section{A R T I C L E I N F O}

\section{Article history:}

Received 7 April 2016

Received in revised form 14 June 2016

Accepted 17 June 2016

Available online 4 July 2016

Editor: D. Barcelo

\section{Keywords:}

Loess Plateau

Runoff

Vegetation change

Ecosystem services

\begin{abstract}
A B S T R A C T
Recently, relationship between vegetation activity and temperature variability has received much attention in China. However, vegetation-induced changes in water resources through changing land surface energy balance (e.g. albedo), has not been well documented. This study investigates the underlying causes of vegetation change and subsequent impacts on runoff for the Northern Shaanxi Loess Plateau. Results show that satellite-derived vegetation index has experienced a significantly increasing trend during the past three decades, especially during 2000-2012. Large-scale ecological restorations, i.e., the Natural Forest Conservation project and the Grain for Green project, are found to be the primary driving factors for vegetation increase. The increased vegetation coverage induces decrease in surface albedo and results in an increase in temperature. This positive effect can be counteracted by higher evapotranspiration and the net effect is a decrease in daytime land surface temperature. A higher evapotranspiration rate from restored vegetation is the primary reason for the reduced runoff coefficient. Other factors including less heavy precipitation, increased water consumption from town, industry and agriculture also appear to be the important causes for the reduction of runoff. These two ecological restoration projects produce both positive and negative effects on the overall ecosystem services. Thus, long-term continuous monitoring is needed.
\end{abstract}

(c) 2016 Elsevier B.V. All rights reserved.

\footnotetext{
* Corresponding author at: College of Tourism and Environment, Shaanxi Normal University, Xi'an 710119, China.

E-mail address: Liangwei@snnu.edu.cn (W. Liang).
} 


\section{Introduction}

Arid and semiarid regions cover $41 \%$ of the Earth's land surface and contain $38 \%$ of the human population. These regions are more ecologically vulnerable, and sensitive to climate change and human activities, the health of which is a critical challenge (Reynolds et al., 2007; Liang et al., 2015; Yang et al., 2014, 2016). In order to address the serious environmental and ecological issues, a series of large-scale ecological restoration projects were carried out throughout the world (Allana et al., 2013), and China has also taken efforts in such actions since the 1950s (Huang et al., 2009). Recently, two large-scale ecological restoration projects, i.e., the Natural Forest Conservation (NFC) project and the Grain for Green (GFG) project, have been launched to improve vegetation coverage in the Loess Plateau of North China (Feng et al., 2013; Liu et al., 2008). Undoubtedly, changes in vegetation directly or indirectly modify biosphere-atmosphere interactions, including the hydrological cycle (Liang et al., 2015) and energy budgets (McVicar et al., 2007; Chapin et al., 2005). A recent research has shown that vegetation growth cools local land surface temperature (Peng et al., 2014; Shen et al., 2015). However, the increased vegetation coverage result in changes in water resources, which is a dominant factor for fragile ecological regions, through inducing changes in land surface energy components, has not been well documented.

The Loess Plateau accounts for $6.6 \%$ of the entire land area of China and sustains $8.5 \%$ of the Chinese population (Fu et al., 2011). However, due to adverse environmental conditions (e.g., sparse vegetation coverage, periodic high intensity rainstorms) and intensified human activities (e.g., over grazing and coal mining) (Liang et al., 2013; Zhang et al., 2008), this region suffers from severe soil erosion and the average annual soil erosion rate of $2000-2008$ is $3180 \mathrm{t} \mathrm{km}^{-2} \mathrm{yr}^{-1}$ under soil erosion control service (Fu et al., 2011). The Northern Shaanxi Loess Plateau (NSLP), located in the middle of the Loess Plateau, is characterized by typical loess hills and gullies. Average sediment modulus in this region of $1960-1999$ is $9370 \mathrm{t} \mathrm{km}^{-2} \mathrm{yr}^{-1}$ (i.e., 3.8 times and 73 times higher than that in the Yellow River basin and average of continents over the world, respectively) (Mu et al., 2010). Severe soil erosion significantly affects environmental quality and social economy (Fu et al., 2011). To address this problem, large number of ecological restoration projects has been implemented for 30 years since the 1980s. But these costly efforts have yield little success during the first 20 years (Liang et al., 2015). Until the recent 10 years, vegetation restoration began to achieve certain effect and vegetation coverage in the NSLP increased from $29.7 \%$ in 1998 to $42.2 \%$ in 2005 (Cao et al., 2009). Consequently, it is essential to investigate these underlying causes of vegetation change.

Numerous studies have attempted to evaluate hydrological effects of vegetation dynamics using different methods such as observation experiments and statistic-based model. Huang et al. (2003) assessed runoff responses to afforestation in a watershed $\left(1.15 \mathrm{~km}^{2}\right)$ on the Loess Plateau using paired watershed approach. However, traditional field experiments are generally constrained to field scale and site level studies may be sensitive to the specific climatic and soil condition (Guo and Shen, 2015). Zhang et al. (2015) establishes a relationship between the change in landscape parameter and vegetation change in a Budyko equation, and quantify the impact of vegetation change on the regional hydrological. However, in the Loess Plateau, there are many non-vegetation measures (e.g. check-dams) and the combined effect of vegetation and non-vegetation makes it a challenge to figure out the impact of vegetation coverage on runoff. Remote sensing products, which have the advantages of broad spatial coverage and high temporal resolution, have been widely used in analyzing the impacts of vegetation coverage change on biophysical properties of land surface (e.g. albedo) (Lü et al., 2015; Xiao, 2014) and thus on water resources changes. Nevertheless, large uncertainties can be involved due to limited scenes of quality images (Kalma et al., 2008; Long and Singh, 2012; Yang and Shang, 2013; Yang et al., 2015). Therefore, combining ground-based observation with remote sensing method is considered as an appropriate approach to evaluate the effects of ecological restoration. Jia et al. (2014) quantified the benefits and equilibrium of the GFG project in NSLP in terms of soil conservation, water yield, evapotranspiration and net primary productivity (NPP) at the grid-cell level, which is not benefit for catchment management. On the other hand, detailed information about spatiotemporal changes in ecological restoration is not readily available, which precludes a comprehensive understanding of its effect.

Our objectives of this study were to: (i) analyze changes in vegetation variable (i.e. normalized difference vegetation index [NDVI]) and hydro-meteorological variables (i.e., runoff, precipitation and temperature) over 1982-2012; (ii) examine the spatiotemporal pattern of ecological restoration changes during 1999-2010; (iii) investigate possible reasons for changes in runoff coefficient (defined as the ratio between runoff depth and precipitation) during 2000-2012 in the China's Loess Plateau.

\section{Methods}

\subsection{Study region}

The Northern Shaanxi Loess Plateau $\left(35^{\circ} 21^{\prime}-39^{\circ} 34^{\prime} \mathrm{N}, 107^{\circ} 28^{\prime}-\right.$ $111^{\circ} 15^{\prime} \mathrm{E}$ ), is located in the middle of the Loess Plateau with an area of 83,990 $\mathrm{km}^{2}$ (see Supplementary Fig. S1), which is characterized by typical loess hills and gullies, and dominated by a semi-arid continental monsoon climate (Jia et al., 2014). Annual average temperature in this region varies from $6.5{ }^{\circ} \mathrm{C}$ in the north to $12.5^{\circ} \mathrm{C}$ in the south and annual average precipitation increases from $250 \mathrm{~mm}$ in the north to $450 \mathrm{~mm}$ in the south, $60-70 \%$ of which occurs from July to September in the form of high intensity rainstorms (Fu et al., 1999). The soil is mainly derived from loess with fine silt to silt in texture which is vulnerable to erosion (Jia et al., 2014). The land-use types are primarily cropland, grassland and forest (Fig. S1b).

\subsection{Data sources}

Evapotranspiration (ET) data used in this study were obtained from Numerical Terra Dynamic Simulation Group (2000 - 2012) (http:// www.ntsg.umt.edu) and a machine-learning algorithm using fluxtower ET measurements (2000 - 2011) (https://www.bgc-jena.mpg. $\mathrm{de} /$ geodb/projects/Data.php). Other MODIS products (i.e., NDVI, albedo, daytime land surface temperature [DLST]) of 2000-2012 were obtained from National Aeronautics and Space Administration (NASA) Earth Observing System (http://reverb.echo.nasa.gov). Global Inventory Modelling and Mapping Studies (GIMMS)-3g NDVI data with a spatial resolution of $8 \mathrm{~km}$ derived from the National Oceanic and Atmospheric Administration (NOAA), and Advanced Very High Resolution Radiometer (AVHRR)-NDVI of 1982-2012 were used in this study. MODIS NDVI have been used for two reasons: (1) AVHRR products cannot provide such energy variables; and (2) Both vegetation variable (MODIS NDVI) and energy variables (albedo, DLST) have the same data source, thus reducing the uncertainty from remote sensing data. The general information of these data products are listed in supplementary Table S1.

Meteorological data including annual mean temperature, annual and daily precipitation from 1982 to 2012 were obtained from the National Climatic Centre (NCC) of the China Meteorological Administration (CMA). Annual runoff data from 1982 to 2012 at 12 hydrological stations were acquired from the Yellow River Conservancy Commission (YRCC). The ecological restoration data of each county including returning cropland to forest, afforestation of barren land, and mountain closure (e.g. prohibition of fuelwood collection and grazing) from 1999 to 2010 were collected from the Forestry Department of Shaanxi Province. 

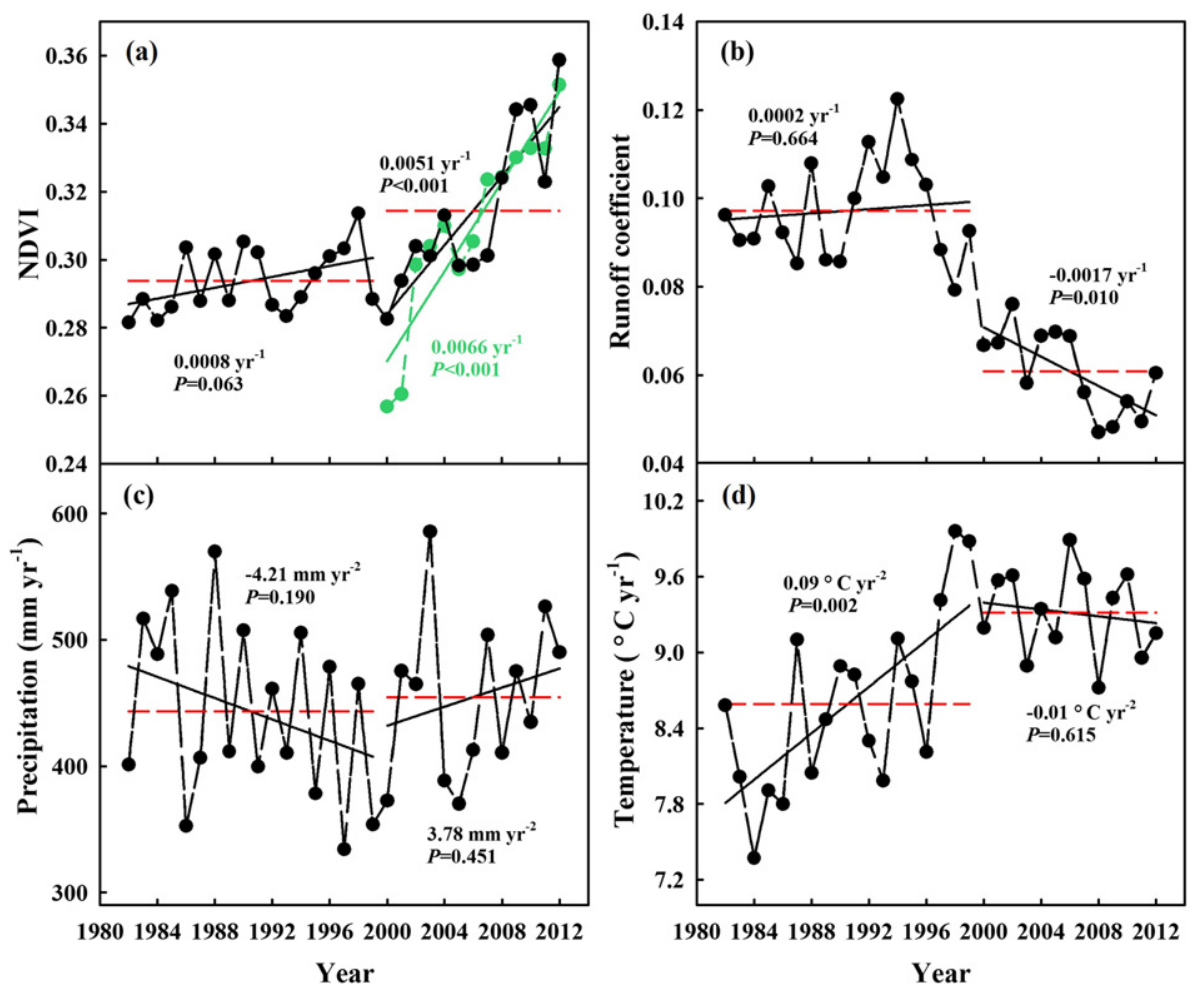

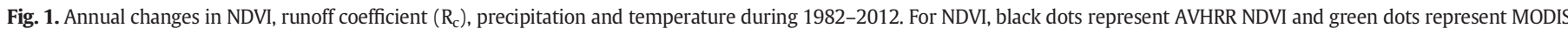
NDVI. The stepped red straight lines represent the mean annual values of each period.

\subsection{Data analysis}

The annual NDVI series of each catchment was generated by averaging each pixel for each year. Similarly, the regional mean time series were also generated for albedo, DLST and ET. Meteorological data including precipitation and temperature were spatially averaged across the study area by the Co-Kriging interpolation algorithm using ArcGIS 10.1, which takes a digital elevation model (DEM) as a third independent variable. Runoff coefficient (Rc) for individual catchment was derived by runoff dividing corresponding precipitation. Linear regression method was used to estimate the trends in these variables (at annual scale). To investigate the relationship among these variables, Pearson's correlation analyses were performed.

\section{Results}

\subsection{Changes in NDVI, runoff, precipitation and temperature}

We detected changes in annual NDVI using two different satellitederived NDVI datasets: AVHRR (1982-2012) and MODIS (20002012). The AVHRR NDVI data showed a significantly positive trend during the entire period 1982-2012 $(P<0.001)$, with an annual increase of $0.002 \mathrm{yr}^{-1}$ (Fig. 1a). However, this increasing trend was not unanimous
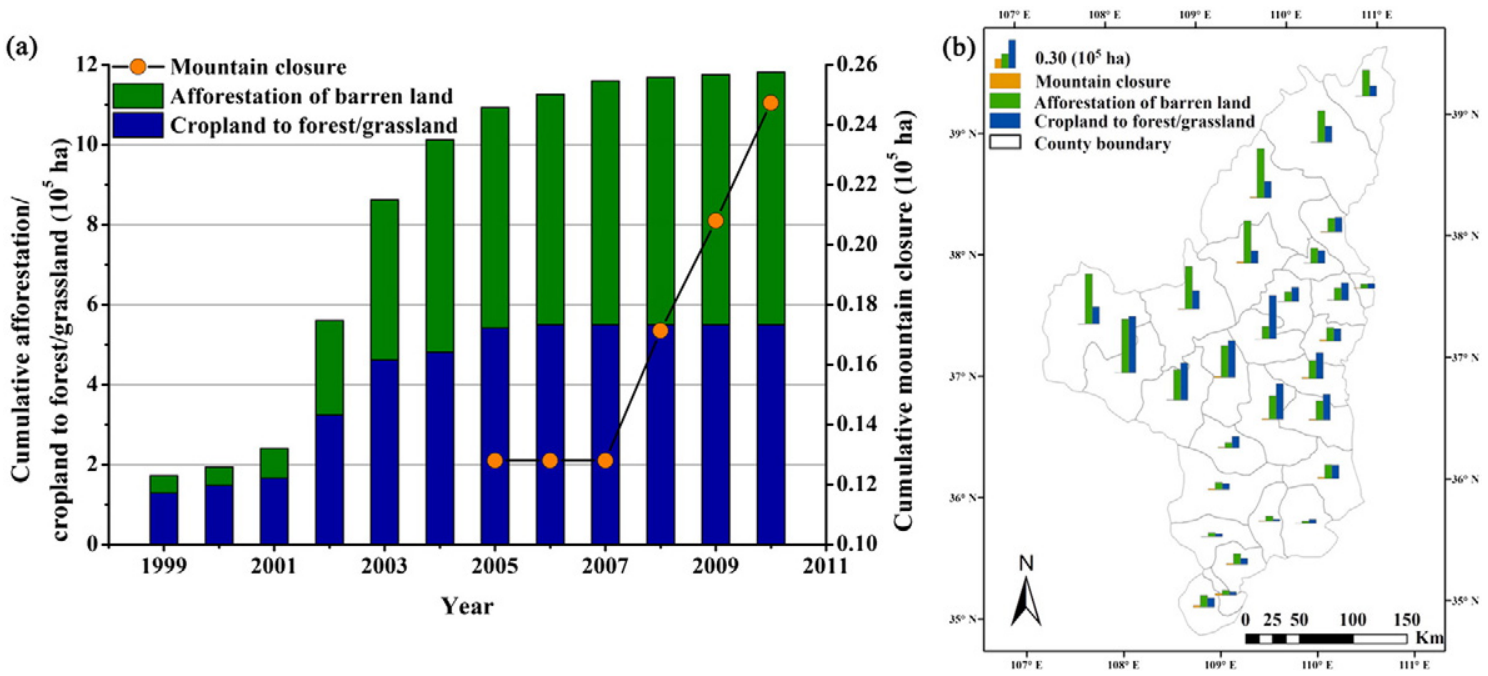

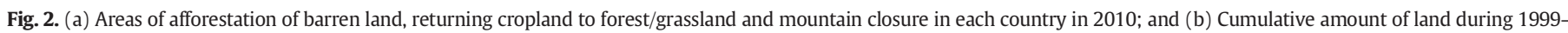
2010. 
before and after 2000. It was shown that the AVHRR NDVI over the NSLP slightly increased during the period 1982-1999 (Fig. 1a). In contrast, during their period of overlap in the 2000s, the two NDVI datasets exhibited similar mean trends, and both showed a significant $(P<0.001)$ increase in the annual NDVI during 2000-2012 in the region (6.4 times for AVHRR and 8.3 times for MODIS higher than that in the former period, respectively). Similarly, $\mathrm{R}_{\mathrm{C}}$ showed relatively stable change during the former period, while a significantly decreasing trend was observed during the recent decade, with a decrease rate of $0.0017 \mathrm{yr}^{-1}$ (Fig. 1b). However, precipitation has no statistically significant trends and changed very little (only increased by $2.6 \%$ ) in the two periods and air temperature even presents a slightly decreasing trend in recent decade (Fig. 1c and d).

\subsection{Temporal and spatial pattern of ecological restoration}

Fig. 2 showed the ecological restoration area about afforestation of barren land, returning cropland to forest/grassland and mountain closure. Generally, it could be found that cumulative area of land was gradually increased during the period 1999-2010, with large increase for 2002 and 2003 (Fig. 2a). After 2005, this region began to focus on natural rehabilitation (i.e., mountain closure), while the other two measures

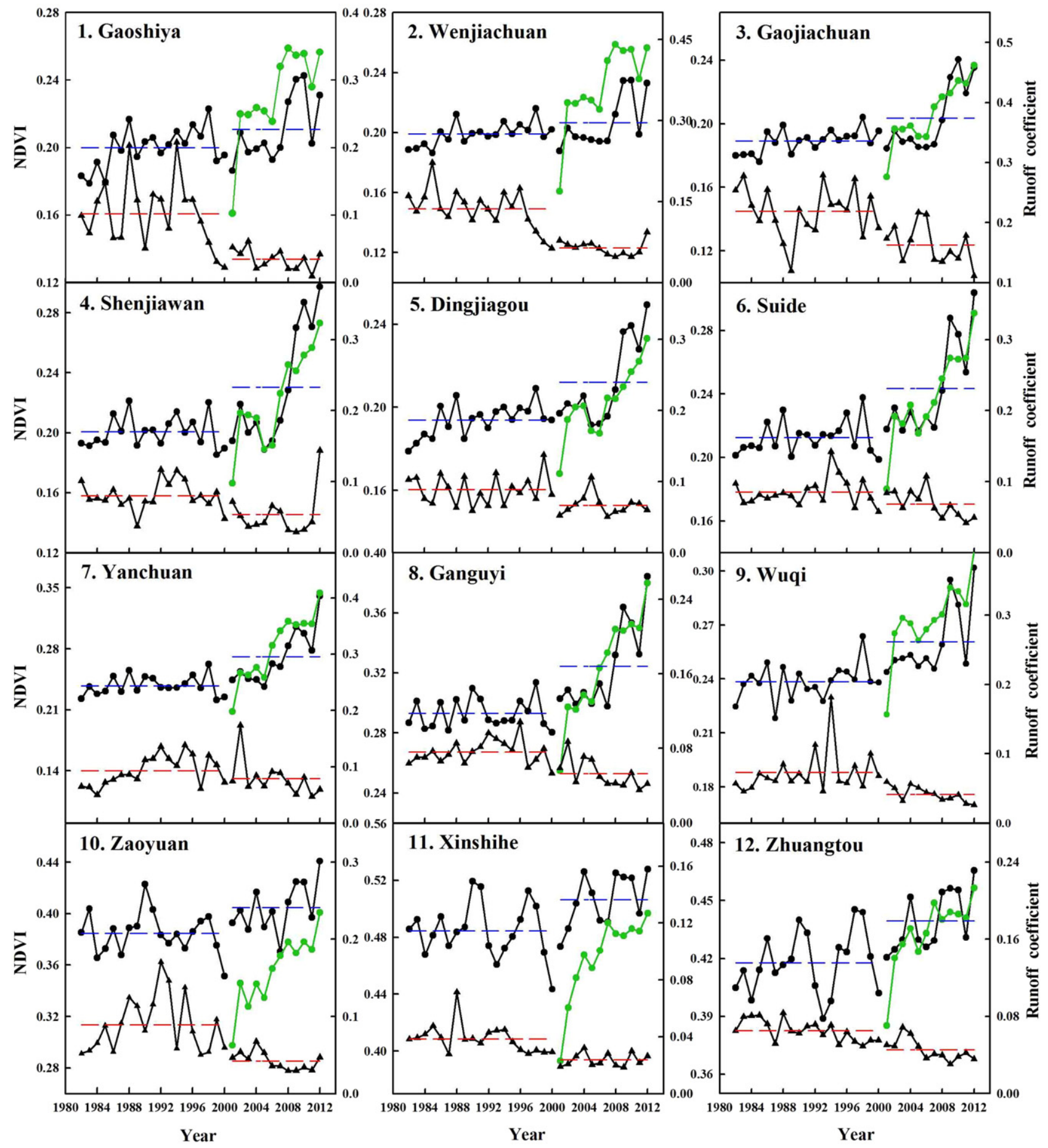

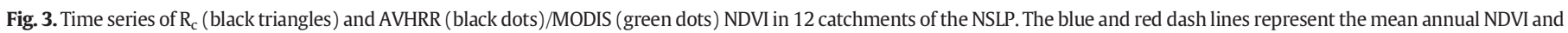
$\mathrm{R}_{\mathrm{c}}$ during different periods, respectively. 
remained stable. By the end of 2010, the NSLP have afforested $6.32 \times 10^{5}$ ha of barren land, converted $5.5 \times 10^{5}$ ha of cropland into forest/grassland and have mountain closure area of $0.25 \times 10^{5}$ ha, respectively. Additionally, there is an obviously spatial difference in the implementation of these measures (Fig. 2b). Ecological restoration measures mainly focus on afforestation in the northwestern parts of the region where soil is sandy, whereas the portion of afforestation and returning cropland to forest/grassland were found almost equal in middle parts (Supplementary Fig. S1b).

\subsection{Possible reasons for changes in runoff}

Fig. 3 shows the inter-annual variation in two dataset NDVI and $R_{c}$ at catchment scale. Similar to the change of whole NSLP, $\mathrm{R}_{\mathrm{C}}$ generally decreased with the increase in NDVI, especially during the period 20002012 (Fig. 3). Meanwhile, $\mathrm{R}_{C}$ showed relatively lower value at the southern catchments than that in the northern ones. To further explore the potential causes of changes in $R_{C}$ after 2000 , a correlation analysis between $\mathrm{R}_{\mathrm{C}}$ and MODIS NDVI, albedo, DLST and ET at regional scale was applied (Fig. 4). Results showed that annual $R_{C}$ was negatively correlated with NDVI and ET across the NSLP $(R=-0.35$ and $R=-0.39$, respectively). On the contrary, the relationship between annual $R_{C}$, albedo and DLST were detected to be positive $(R=0.58$ and $R=0.30$, respectively). Both negative and positive relationship passed the significant test at 0.001 significance level.

At catchment scale, the relationship between MODIS NDVI, albedo, DLST and ET was also investigated. As expected, it was found that annual NDVI in all catchments were significantly negative correlated with albedo and DLST (Fig. 5). The average correlation coefficients were -0.76 and -0.73 over the 12 catchments, respectively. In contrast, NDVI and ET showed a positively correlated relationship (eight of them were statistically significant at 0.05 significance level) with average $R$ of 0.59 . In addition, these positive correlation relationship between NDVI and ET estimated in the machine-learning algorithm using flux-tower measurements [https://www.bgc-jena.mpg.de/geodb/projects/Data.php], were more robust (average correlation coefficient is above 0.85 ) with all catchments being statistically significant $(P<0.001)$ (Fig. S2).

\section{Discussion}

\subsection{Driving factors of vegetation change}

A great deal of large-scale vegetation restoration projects (such as the Three Norths Shelter Forest System Project, TNSFSP) as well as

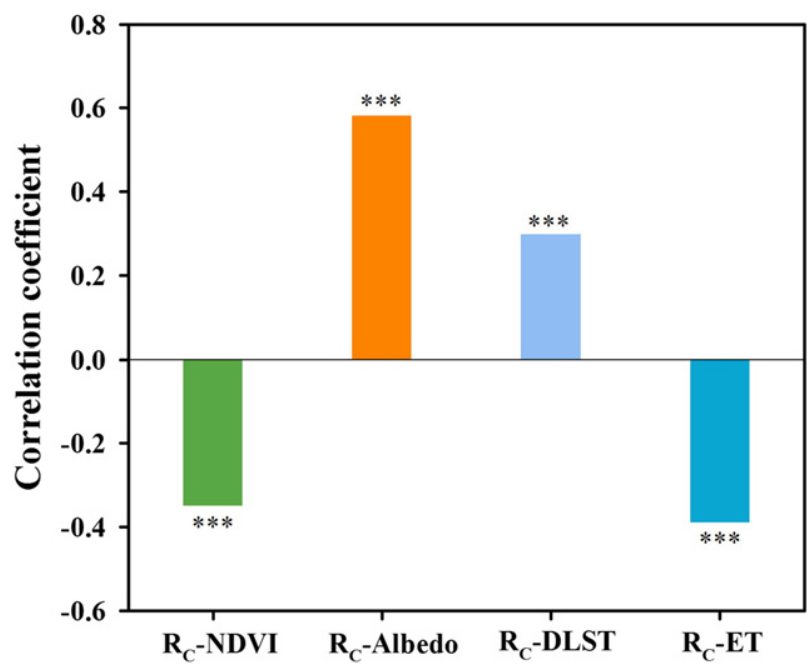

Fig. 4. Relationships between $\mathrm{R}_{\mathrm{c}}$ and NDVI, albedo, DLST and ET during 2000-2012. ${ }^{* * *}$ indicates the 0.001 significance levels. many local projects, have been launched by the Chinese government during the past three decades (Liu et al., 2008). These projects not only cost plenty of labor and material, but also much financial support. For example, from 1978 to 2000, 7.27 billion yuan had been invested in the TNSFSP (Zhang and Song, 2003). Nevertheless, these costly efforts have yield little success in improving vegetation coverage (Fig. 1a). This can be interpreted as vegetation restoration is largely controlled by soil water availability in arid and semi-arid regions (Porporato et al., 2002; Chen et al., 2010), and artificial trees can consume more water than natural native species (Wang et al., 2008). During rainy seasons, precipitation is not sufficient to replenish the soil water storage (Chen et al., 2010), and finally resulting in artificial forest and grassland degradation during drought years. Statistics show that the overall survival rate of trees planted during afforestation projects has been only $15 \%$ across arid and semiarid northern China since 1949 (Tong et al., 2004). On the other hand, the fact is that the Chinese State Forestry Administration has been enthusiastic about tree planting and regeneration, but not necessarily so with restoring grass coverage or natural re-vegetation.

In reality, natural ecosystems that are not damaged too badly have a self-repair ability through natural processes (Aide and Grau, 2004; Yang et al., 2014). Therefore, the recent ecological restoration projects such as the NFC project and GFG project put more emphasis on natural rehabilitation (Fig. 2). In addition, the warming climate extends the length of the growing season and may intensify maximum rates of productivity (Shen et al., 2015). As a result, the satellite-derived vegetation index (NDVI) observed a significantly increasing trend in the most recent decade (Fig. 1a). However, precipitation and temperature, which are key climatic factors determining vegetation growth, changed slightly during the same period (Fig. 1c and d). Therefore, we speculate that recent large-scale ecological restoration, especially the NFC project and GFG project, is the primary driving factor for vegetation coverage increase. Similar result were also reported by Zhang et al. (2013) and Xiao (2014) who state that vegetation coverage on the Loess Plateau exhibited overall increases after the implementation of the GFG project.

\subsection{Runoff response to vegetation change}

Vegetation change may affect greatly on precipitation distribution ratio between actual evapotranspiration and runoff (Liang et al., 2015; Donohue et al., 2007; Li et al., 2013). NDVI in all catchments presented an obvious increasing trend while Rc presented an opposite trend of 2000-2012 (Fig. 3). The positive correlation between NDVI and ET (Fig. 5) can be the possible reason for runoff reduction. The soil type in the NSLP is the loessial soil, namely the soil has a light color (i.e., yellow) and vegetation albedo is relatively darker, which may result in the decrease of albedo and a positive effect on temperature. Moreover, when the net shortwave radiation (the difference between the incoming shortwave radiation and the shortwave radiation reflected by the surface) increases, there will be an increase in the longwave radiation emitted from the surface into the atmosphere. However, this extra energy, which results from lower albedo, can be dissipated as enhanced vegetation transpiration and soil evaporation.

Afforestation and grass-planting can intercept precipitation, improve the soil structure and increase infiltration (Miao et al., 2010; Xu, 2011). In addition, bark crack and leaf litter can result in the relatively higher soil surface roughness (Xu, 2012), all of which will greatly reduce runoff. Sun et al. (2006) shows that forestation practices may reduce water yield up to $50 \%$ especially in the temperate zones of northern China such as the Loess Plateau, which is also supported by Feng et al. (2012) who find that water yield have decreased at an annual rate of $1-48 \mathrm{~mm}$ in $38 \%$ part of the Loess Plateau.

\subsection{Other factors' effects on runoff}

Vegetation restoration is one of the major causes for the decreased Rc in recent years, but there are other factors that may be accelerate 

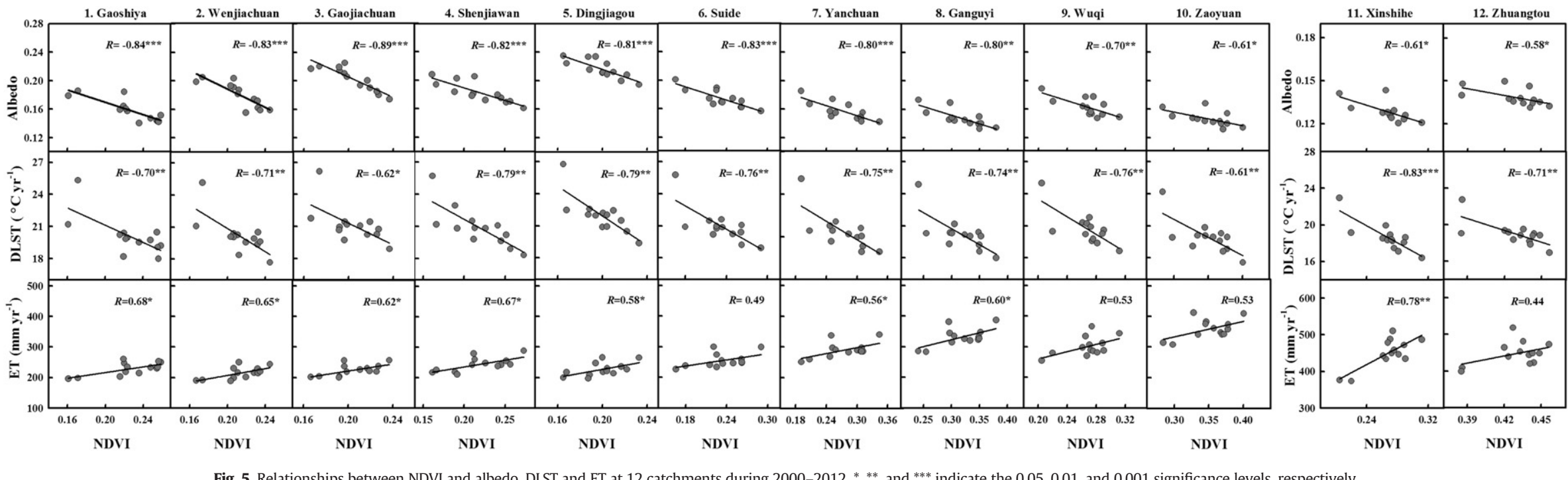

Fig. 5. Relationships between NDVI and albedo, DLST and ET at 12 catchments during 2000-2012. * **, and ${ }^{* * *}$ indicate the $0.05,0.01$, and 0.001 significance levels, respectively 
runoff decrease. For example, in order to meet the demands of the development of city, agriculture (i.e., irrigation) and industry, the withdrawal water of region between Toudaoguai and Longmen station (almost covers the study area) from the Yellow River increases from 1.04 billion $\mathrm{m}^{3}$ in 2000 to 1.92 billion $\mathrm{m}^{3}$ in 2012, having nearly doubled in the past ten years (YRCC, 2000; YRCC, 2012). The number of reservoir and check-dam increased rapidly over the past few decades. A recent study by Xu et al. (2010) shows that the total storage capacity of all registered reservoirs was to be $72 \mathrm{~km}^{3}$, which is much higher than the basin's 2000-2010 mean annual runoff (i.e., $23.6 \mathrm{~km}^{3}$ ). In addition, in our study area, especially in the northern part of the region such as Kuye River catchment (see Fig. S1, catchment 3), there are many of coal mines. The amount of coal mining in this catchment slowly increased from 1987 to 1997 (on average $<2 \times 10^{4}$ ton), while it increased rapidly after that and reached $13.2 \times 10^{4}$ ton in 2006 (Liang et al., 2013). Obviously, the intensive mining activities would have a negative impact on the groundwater system, and indirectly lead to a reduction in runoff. Precipitation type changes may be also an important driver of variability in the water balance. In the Loess Plateau, heavy precipitation is the major source of surface runoff. However, over the NSLP region, both the number of precipitation days (NPD) and precipitation intensity (PI) of heavy precipitation ( $>25 \mathrm{~mm}$ per day) have been decreasing for the past 30 years (Fig. S3 and Table S2). Compared with the period 1982-1989, NPD and PI during the recent 13 years (2000-2012) decreased by $18.6 \%$ and $23.3 \%$, respectively (Table S2). The similar result can be also found in 12 catchments, particular in Xinshihe (Fig. S4).

\subsection{Implications}

Mountain closure takes full use of the ability of natural ecosystem recovery and accelerates the growth of vegetation, which is considered a fast, cheap and lenient method for the rehabilitation of degraded lands (Mengistu et al., 2005). Nevertheless, Cheng et al. (2014) states that long-term grazing exclusion has a negative impact on species generation and ecosystem stability, indicating that, to avoid degradation, management of the natural resources in the enclosures has to keep the balance between growth and harvest. With the recovery of native and cultivated plant species during 15 years for implementation of the NFC and GFG project (Wang et al., 2013), it is suggested that the recovery grassland can be used for mowing once every two years and light grazing (two sheep/ha) (Cheng et al., 2014). In addition, latest report states that further expanding the implementation of GFG project will reduce the available farmland and thus lead to local deficits of food supplies (Chen et al., 2015). By contrast, our results showed that the DLST presented a significantly decreasing trend, which can be related to the increase of vegetation coverage (Fig. 5). It is strongly consistent with other similar studies in the Tibetan Plateau (Shen et al., 2015). This indicates that vapor released from the plant foliage may benefit the residents by climate regulation in terms of improving temperature and moisture (Jia et al., 2014; Foley et al., 2003). In addition, the large-scale ecological restoration enhances soil conservation through reducing water amount and velocity as well as consequent sediment loads. However, it is still not clear whether the effects of these large-scale ecological restorations on the whole ecosystem services are positive at long time scale and long-term continuous monitoring is needed.

\section{Acknowledgments}

This work was funded by the National Natural Science Foundation of China (41571130083), the National Special Program on Basic Science and Technology Research of China (2014FY210100) and the Fundamental Research Funds for the Central Universities (GK201603072).

\section{Appendix A. Supplementary data}

Supplementary data to this article can be found online at http://dx. doi.org/10.1016/j.scitotenv.2016.06.141.

\section{References}

Aide, T.M., Grau, H.R., 2004. Ecology. Globalization, migration, and Latin American ecosystems. Science 305, 1915-1916.

Allana, J.D., McIntyre, P.B., Sigrid, D.P.S., Halpern, B.S., et al., 2013. Joint analysis of stressors and ecosystem services to enhance restoration effectiveness. P. Natl. Acad. Sci. USA $110,372-377$

Cao, S., Chen, L., Yu, X., 2009. Impact of China's grain for green project on the landscape of vulnerable arid and semi-arid agricultural regions: a case study in northern Shaanxi Province. J. Appl. Ecol. 46, 536-543.

Chapin, F.S., Sturm, M., Serreze, M.C., McFadden, J.P., et al., 2005. Role of land-surface changes in Arctic summer warming. Science 310, 657-660.

Chen, L., Wang, J., Wei, W., Fu, B., Wu, D., 2010. Effects of landscape restoration on soil water storage and water use in the Loess Plateau region. China. Forest Ecol. Manag. 259, 1291-1298.

Chen, Y., Wang, K., Lin, Y., et al., 2015. Balancing green and grain trade. Nat. Geosci. 8, 739-741.

Cheng, J.M., Jing, Z.B., Jin, J.W., Gao, Y., 2014. Restoration and utilization mechanism of degraded grassland in the semi-arid region of Loess Plateau. Scientia Sinica Vitae, p. 44 http://dx.doi.org/10.1360/052013-280 (in Chinese).

Donohue, R., Roderick, M., McVicar, T., 2007. On the importance of including vegetation dynamics in Budyko's hydrological model. Hydrol. Earth Syst. Sci. 11, 983-995.

Feng, X.M., Sun, G., Fu, B., et al., 2012. Regional effects of vegetation restoration on water yield across the Loess Plateau. China. Hydrol. Earth Syst. Sci. 16, 2617-2628.

Feng, X., Fu, B., Lu, N., Zeng, Y., Wu, B., 2013. How ecological restoration alters ecosystem services: an analysis of carbon sequestration in China's loess plateau. Sci. Rep. 3. http://dx.doi.org/10.1038/srep02846.

Foley, J.A., Costa, M.H., Delire, C., Ramankutty, N., Snyder, P., 2003. Green surprise? How terrestrial ecosystems could affect earth's climate. Front. Ecol. Environ. 1, 38-44.

Fu, B., Ma, K., Zhou, H., Chen, L., 1999. The effect of land use structure on the distribution of soil nutrients in the hilly area of the Loess Plateau. China. Chin. Sci. Bull. 44, 732-736.

Fu, B., Liu, Y., Lü, Y., et al., 2011. Assessing the soil erosion control service of ecosystems change in the Loess Plateau of China. Ecol. Complex. 8, 284-293.

Guo, Y., Shen, Y., 2015. Quantifying water and energy budgets and the impacts of climatic and human factors in the Haihe River basin, China: 1. Model and validation. J. Hydrol. 528, 206-216.

Huang, M., Zhang, L., Gallichand, J., 2003. Runoff responses to afforestation in a watershed of the Loess Plateau. China. Hydrol. Processes. 17, 2599-2609.

Huang, Y., Cai, J., Yin, H., Cai, M., 2009. Correlation of precipitation to temperature variation in the Huanghe River (Yellow River) basin during 1957-2006. J. Hydrol. 372, 1-8.

Jia, X., Fu, B., Feng, X., et al., 2014. The tradeoff and synergy between ecosystem services in the grain-for-green areas in northern Shaanxi. China. Ecol. Indic. 43, 103-113.

Kalma, J.D., McVicar, T.R., McCabe, M.F., 2008. Estimating land surface evaporation: a review of methods using remotely sensed surface temperature data. Surv. Geophys. 29, 421-469.

Li, D., Pan, M., Cong, Z., Zhang, L., Wood, E., 2013. Vegetation control on water and energy balance within the Budyko framework. Water Resour. Res. 49, 969-976.

Liang, K., Liu, C., Liu, X., Song, X., 2013. Impacts of climate variability and human activity on streamflow decrease in a sediment concentrated region in the middle Yellow River. Stoch. Env, Res. Risk A. 27, 1741-1749.

Liang, W., Bai, D., Wang, F., Fu, B., et al., 2015. Quantifying the impacts of climate change and ecological restoration on streamflow changes based on a Budyko hydrological model in China's Loess Plateau. Water Resour. Res. http://dx.doi.org/10.1002/ 2014 wr016589.

Liu, J., Li, S., Ouyang, Z., Tam, C., Chen, X., 2008. Ecological and socioeconomic effects of China's policies for ecosystem services. P. Natl. Acad. Sci. USA. 105, 9477-9482.

Long, D., Singh, V.P., 2012. A modified surface energy balance algorithm for land (MSEBAL) based on a trapezoidal framework. Water Resour. Res. 48, W02528.

Lü, Y., Zhang, L., Feng, X., Zeng, Y., et al., 2015. Recent ecological transitions in China: greening, browning, and influential factors. Sci. Rep. 5. http://dx.doi.org/10.1038/ srep08732.

McVicar, T.R., Van Niel, T.G., Li, L., et al., 2007. Spatially distributing monthly reference evapotranspiration and pan evaporation considering topographic influences J. Hydrol. 338, 196-220.

Mengistu, T., Teketay, D., Hulten, H., Yemshaw, Y., 2005. The role of enclosures in the recovery of woody vegetation in degraded dryland hillsides of central and northern Ethiopia. J. Arid Environ. 60, 259-281.

Miao, C., Ni, J., Borthwick, A.G., 2010. Recent changes of water discharge and sediment load in the Yellow River basin. China. Prog. Phys. Geog. 34, 541-561.

Mu, X., Dai, H., Gao, P., Wu, Y., Zhang, C., 2010. Spatial-temporal characteristics of rainfall erosivity in northern Shaanxi region in the Loess Plateau. J. Arid Land resour. Environ. 24, 37-43 (in Chinese).

Peng, S.S., Piao, S.L., Zeng, Z.Z., et al., 2014. Afforestation in China cools local land surface temperature. P. Natl. Acad. Sci. USA. 111, 2915-2919.

Porporato, A., D'odorico, P., Laio, F., Ridolfi, L., Rodriguez-Iturbe, I., 2002. Ecohydrology of water-controlled ecosystems. Adv. Water Resour. 25, 1335-1348.

Reynolds, J.F., Stafford Smith, D.M., Lambin, E.F., et al., 2007. Global desertification: building a science for dryland development. Science 316, 847-851. 
Shen, M., Piao, S.L., Jeong, S.J., et al., 2015. Evaporative cooling over the Tibetan Plateau induced by vegetation growth. P. Natl. Acad. Sci. USA. 112, 9299-9304.

Sun, G., Zhou, G., Zhang, Z., et al., 2006. Potential water yield reduction due to forestation across China. J. Hydrol. 328, 548-558.

Tong, C., Wu, J., Yong, S.P., Yang, J., Yong, W., 2004. A landscape-scale assessment of steppe degradation in the Xilin River basin, Inner Mongolia. China. J. Arid Enviro. 59, 133-149.

Wang, L., Wang, Q., Wei, S., Shao, M.a., Li, Y., 2008. Soil desiccation for Loess soils on natural and regrown areas. For. Ecol. Manag. 255, 2467-2477.

Wang, S., Fu, B., Gao, G., Liu, Y., Zhou, J., 2013. Responses of soil moisture in different land cover types to rainfall events in a re-vegetation catchment area of the Loess Plateau. China. Catena. 101, 122-128.

Xiao, J., 2014. Satellite evidence for significant biophysical consequences of the "grain for green" program on the Loess Plateau in China. J. Geophys. Res. Biogeosci. 119, 2261-2275.

Xu, J., 2011. Variation in annual runoff of the Wudinghe River as influenced by climate change and human activity. Quat. Int. 244, 230-237.

$\mathrm{Xu}, \mathrm{J} ., 2012$. Effects of climate and land-use change on green-water variations in the middle Yellow River. China. Hydrol. Sci. J. 58, 106-117.

Xu, K., Milliman, J.D., Xu, H., 2010. Temporal trend of precipitation and runoff in major Chinese Rivers since 1951. Glob. Planet. Chang. 73, 219-232.

Yang, Y.T., Shang, S.H., 2013. A hybrid dual source scheme and trapezoid framework based evapotranspiration model (HTEM) using satellite images: algorithm and model test. J. Geophys. Res. Atmos. 118, 2284-2300.

Yang, Y.T., Long, D., Guan, H.D., Scanlon, B., Simmons, C.T., Jiang, L., Xu, X., 2014. GRACE satellite observed hydrological controls on interannual and seasonal variability of surface greenness over mainland Australia. J. Geophys. Res. Biogeosci. 119, $2245-2260$

Yang, Y.T., Long, D., Guan, H.D., Liang, W., Simmons, C.T., Batelaan, O., 2015. Comparison of three dual-source remote sensing evapotranspiration models during the MUSOEXE-12 campaign: revisit of model physics. Water Resour. Res. 51, 3145-3165.

Yang, Y.T., Guan, H.D., Batelaan, O., et al., 2016. Contrasting responses of water use efficiency to drought across global terrestrial ecosystems. Sci. Rep. 6, 23284.

YRCC, Yellow River Conservancy Commision. 2000 Water Resources Bulletin of the Yellow River, <http://www.yellowriver.gov.cn/other/hhgb/2000.htm> (Accessed: 20th February 2016).

YRCC, Yellow River Conservancy Commision. 2012 Water Resources Bulletin of the Yellow River, <http://www.yellowriver.gov.cn/other/hhgb/2012szygb/2012szygb. html> (Accessed: 20th February 2016).

Zhang, L.X., Song, Y.Q., 2003. Efficiency of the three-north forest shelterbelt program. Acat Scientiarum Naturalium Universitatis Pekinensis. 39, 594-600 (in Chinese).

Zhang, X.P., Zhang, L., Zhao, J., Rustomji, P., Hairsine, P., 2008. Responses of streamflow to changes in climate and land use/cover in the loess plateau. China. Water Resour. Res. 44. http://dx.doi.org/10.1029/2007WR006711.

Zhang, B., Wu, P., Zhao, X., Wang, Y., Gao, X., 2013. Changes in vegetation condition in areas with different gradients (1980-2010) on the Loess Plateau. China. Environ. Earth Sci. 68, 2427-2438.

Zhang, S., Yang, H., Yang, D., Jayawardena, A., 2015. Quantifying the effect of vegetation change on the regional water balance within the Budyko framework. Geophys. Res. Lett. http://dx.doi.org/10.1002/2015GL066952. 